\title{
Fragments of Glass Bangles from Krek 52/62 and Their Implications for the Dating of the Mimotien Culture
}

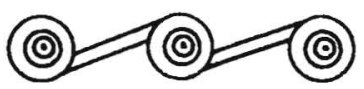

\author{
MIRIAM NOËL HAIDLE
}

Louis MALlereT (1959) DEVOTED a complete article to the circular earthworks limited to the red soil region of east Cambodia and South Viet Nam (Fig. 1). Since this first detailed mention, the homogeneous site group, which has outer walls and inner ditches, has been set in a Neolithic context. Few of the now many known structures have been excavated, including B. P. Groslier's site in 1962, and other excavations and sondages from the last five years. Even so, only a few detailed analyses of the finds discovered at circular earthwork sites have been presented (cf. Albrecht et al. 2001). Up to now, our knowledge on the material culture and the dating of these Mimotien structures was based on a few surface finds and some short notes by Bernard Phillipe Groslier (1966a, 1966b), who defined the cultural complex.

Rather vague and unfounded dates of the newly introduced Mimotien culture are given in the literature (Fig. 2): Groslier (1966a) himself dated it as Neolithic, between 2500 and 1000 B.C., in a short paragraph in his famous book on Indochina, whereas in an article published in the same year (1966b:81), he dated it between 1500 and 500 B.c. Edmond Saurin (1969:32-33) classified it as Néolithique supérieur. Jean-Pierre Carbonnel $(1979: 224)$ summarized the scant results of B. P. Groslier: "Fourteen late Neolithic layers were listed, with a succession of three polished adz types, and the name 'Mimotien' has been given to this succession. The Mimotien has not so far been defined, either in time or in relation to other known South East Asian industries." Carbonnel himself (1979) did some radiocarbon dating on organic material from tumuli at the Chup rubber plantation pointing to a Neolithic provenience. He set the tumuli in association with the Mimotien circular earthworks further to the east: the relationship between the two site types, however, still lacks evidence.

In the 1980s, several Vietnamese researchers postulated a metal age dating for the Mimotien circular earthworks. Luong Ninh (1985, cited in Nguyen Trung Do 1999) determined that the site group was of late Bronze to early Iron Age

Miriam Noël Haidle is a lecturer at the University of Tübingen, Germany, and the Royal University of Fine Arts, Phnom Penh, Cambodia.

Asian Perspectives, Vol. 40, No. 2 (c) 2002 by University of Hawai'i Press. 


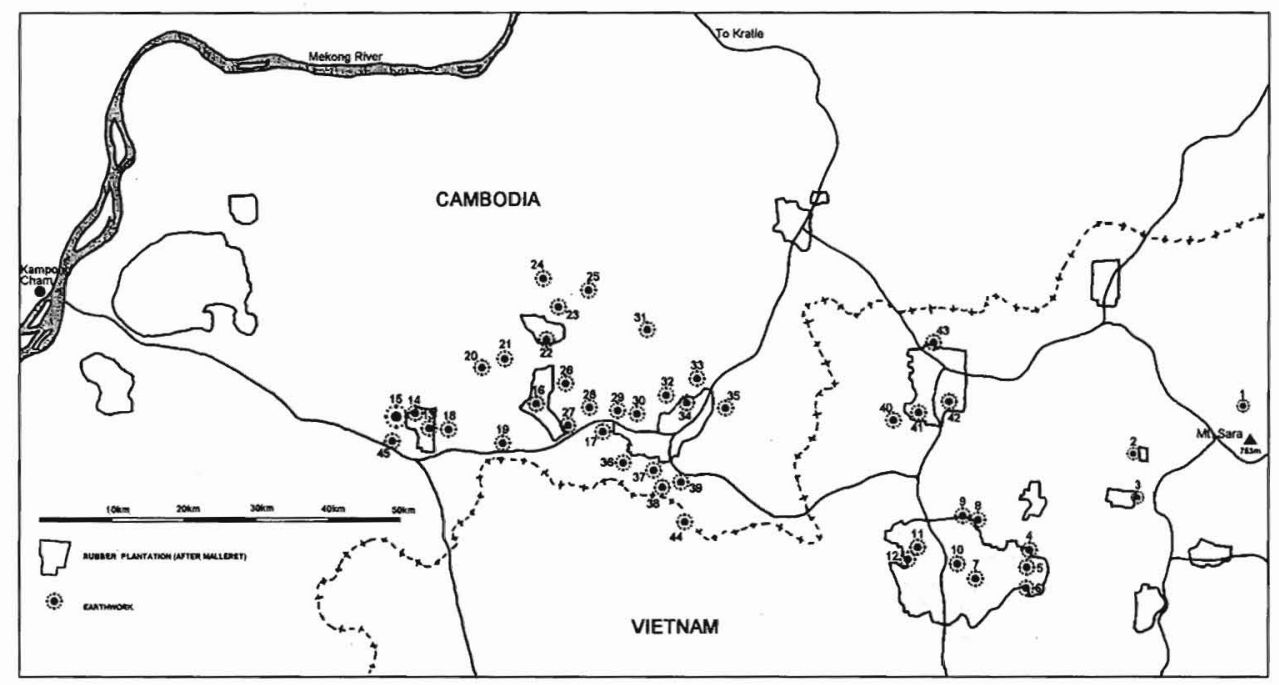

Fig. 1. Distribution of the circular earthworks of the Mimotien complex in the red soil area of southeastern Cambodia and adjacent Viet Nam. 1-14: Malleret \#1-14. 15: Krek 52/62 (Malleret \#15). 16: Chamkar Thmey (Malleret \#16?). 17: Memot (Malleret \#17?). 18: Chi Peang. 19: Phoum Beng. 20: Chong. 21: Groslier site. 22: Kampoan. 23: Huon Khim. 24: Chok Kley. 25: Phnom Penh. 26: Koki. 27: Samrong. 28: Mukkras. 29: Trobek. 30: Ngeu. 31: Houng. 32: Phnom Lumpeng I. 33: Phnom Lumpeng II. 34: Banteay Phcong. 35 Maraon. 36: Trameng. 37: Peam. 38: Beng. 39: O'Angkam. 40: Tatee. 41: An Binh. 42: Loc Ninh. 43: Loc Hoa. 44: Chanmul. 45: Huoch.

origin within the second to first millennium B.C. Correspondingly, Ngyuen Trung Do estimated an age of 3500 to 2500 B.P. based on comparative studies of artifact samples from other prehistoric sites in Nambo (Nguyen Trung Do 1984, 1997, cited in Do 1999). Nguyen Van Long (1986, cited in Nguyen Trung Do

$$
\begin{array}{llllll}
B C 4000 & 3000 & 2000 & 1000 & 0 & 1000 \text { AD }
\end{array}
$$

Malleret 1959

Groslier 1966 a

Groslier 1966 b

Saurin 1969

Carbonnel 1979

Luong Ninh 1985

Nguyen Trung Do 1984

Nguyen Van Long 1986

Mourer 1994

Pham Duc Manh 1996

Kojo \& Sytha 1997

Dega 1999
NEOLITHIC

\section{Néolithique supérieure}

late Neolithic

Fig. 2. Previous datings of the Mimotien complex given in the literature. 
1999) dated the circular sites even later, to 2500 to 2000 B.P. Combining the views of previous authors, Roland Mourer (1994, table 4) described the Mimotien as Neolithic rather than from the metal ages, giving a time range from 3400 B.C. (with question marks), or, more assuredly, from 1280 B.C. to A.D. 800.

In the 1990 s new attempts were made to work on the circular earthworks. A - Vietnamese publication (Pham Duc Manh 1996:70) discusses the group of sites as Neolithic according to B. P. Groslier (1966a), E. Saurin (1971), and P. Bellwood (1978). A different date, attributed to the pre-Khmer Dvaravati period by H.G.Q. Wales (1957), is mentioned. Yasushi Kojo and Pheng Sytha (1997:181, 187) adopt a Neolithic date according to B. P. Groslier (1966a), R. Mourer (1977), and J.-P. Carbonnel (1979). Michael F. Dega (1999:189) interpreted the Mimotien as "an early autochthonous development, perhaps as early as 3000-2000 B.C." Up to this year, only a few radiocarbon dates on the organic temper of potsherds have been presented (Albrecht et al. 2001; Dega et al. 2000), which, however, have to be viewed cautiously because of problems in sample processing (see below). No other organic material suitable for absolute dating has been preserved in the occupational layers of the circular earthworks due to the very acidic conditions $(\mathrm{pH}<4)$ of the red soils in this area.

\section{GLASS BANGLES IN MIMOTIEN CONTEXT}

In 1996, a German team lead by Gerd Albrecht began its work on circular earthworks at Krek 52/62 (Malleret No. 15) (Fig. 3) as a teaching project at the Royal University of Fine Arts, Phnom Penh, in cooperation with the University of Tübingen and financed by the German Academic Exchange Service (DAAD) (Albrecht and Haidle 1999).

Our group began with the same presumption as previous researchers: the Neolithic origin of these Mimotien sites. The preliminary survey in 1996 as well as the first campaign in 1997 gave no hint of anything other than a Neolithic assemblage consisting of hundreds of potsherds and a variety of stone artifacts (Albrecht et al. 2001).

The 1998 field campaign, however, yielded an extraordinary surprise. A fragment of a glass bracelet was uncovered in Unit II, square M9. As glass finds in Southeast Asia are reliably dated no earlier than an Iron Age context after c. 500 B.C. (Glover and Henderson 1995 : 147; Reinecke and Le Duy Son 2000:16-17), this discovery was beyond anything expected at a so-called Neolithic site. All find circumstances were checked very carefully. The fragment, broken into one very small and two larger pieces, was found in situ in the context of a dense ceramic and stone artifact distribution next to one of the two identified pits. Vertically, the find was located in the upper part $(191 \mathrm{~cm}$ above local zero) but well within the most densely packed zone of the occupational layer (Fig. 4).

Neither the color nor texture of the soil gave any hint of modern disturbances, nor were other indications observed nearby pointing to animal or human activities in more recent times than the main occupation. There is no evidence that the glass fragment is more likely to be intrusive than any of the other finds in $M 9$, which fit very well into the known artifact range of circular earthworks. For two years the glass bangle remained unique. In the spring 2000 and winter $2000-$ 2001 campaigns at Krek 52/62, however, four more glass bangle fragments were 


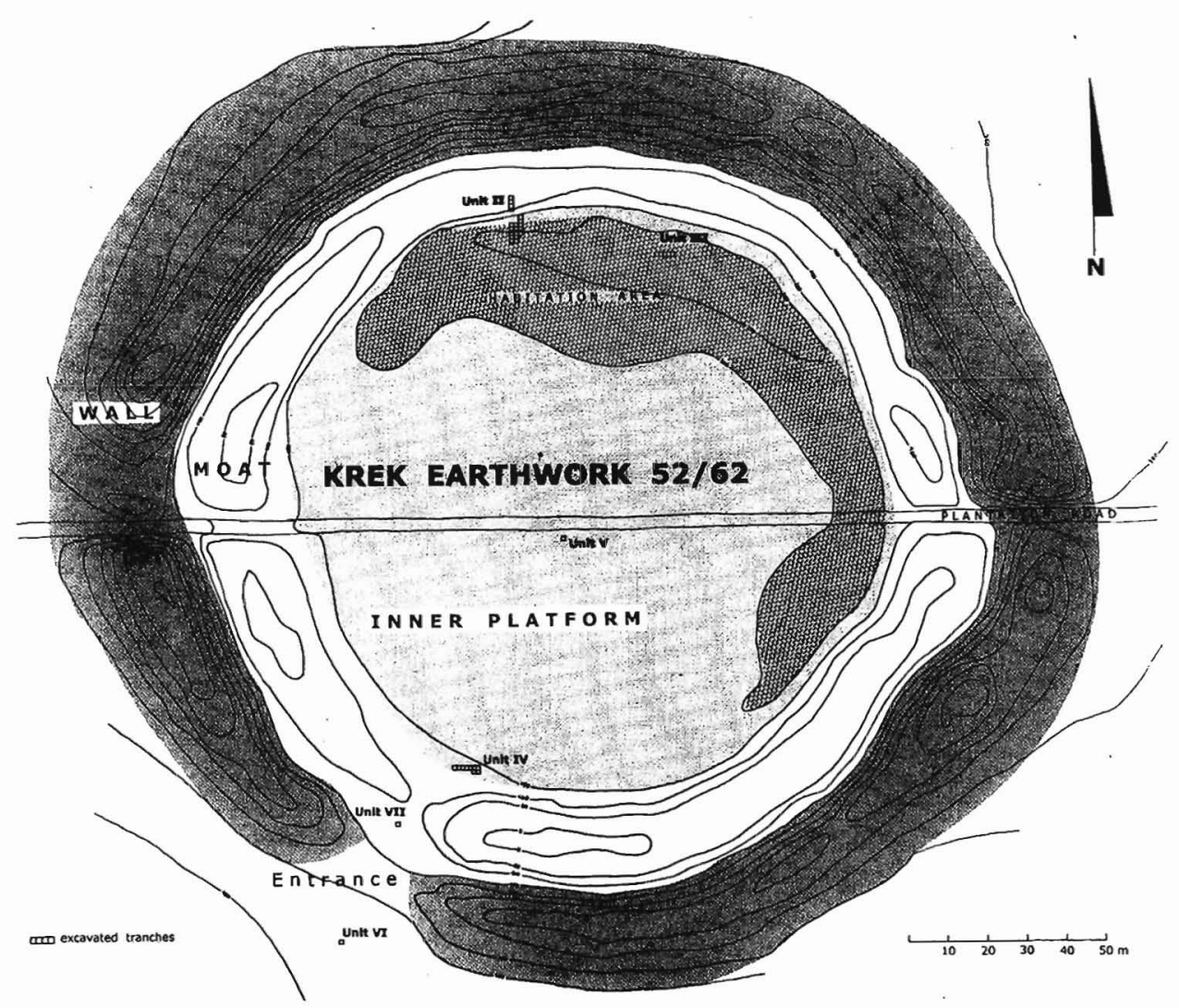

Fig. 3. Circular earthwork Krek 52/62 (Malleret \#15). The fragments of the glass bangles were found in Unit II.

discovered, again in the uppermost zone of the occupational layer in Unit II (Table 1).

All bracelets are made of light to dark green or blue-green translucent glass (Figs. 5, 6) and show a triangular to house-shaped cross section. The dimensions of the bangles vary slightly: their widths range from 11.3 to $13.5 \mathrm{~mm}$, the height from 5.0 to $6.8 \mathrm{~mm}$. Their width/height ratio lies between 1.95 and 2.26. Except for one (M12/3, Fig. 6) all the fragments are faceted on both sides giving the overall triangular cross section a more house-shaped appearance. The inner diameter of only one piece $(\mathrm{M} 9 / 13)$ could be reconstructed to $58 \mathrm{~mm}$. Their state of preservation is very good, nearly no signs of weathering can be observed.

\section{CHEMICAL ANALYSES OF THE KREK GLASS FRAGMENTS}

The chemical composition of the glass from Krek 52/62 was analyzed using a microprobe at the Geochemical Institute of the University of Göttingen and the Mineralogical Institute of the University of Tübingen. Fourteen components were measured on different parts of the samples: the means of the results are shown in Table 2. Except for M12/3, all the glass has soda as a main flux with a minor por- 


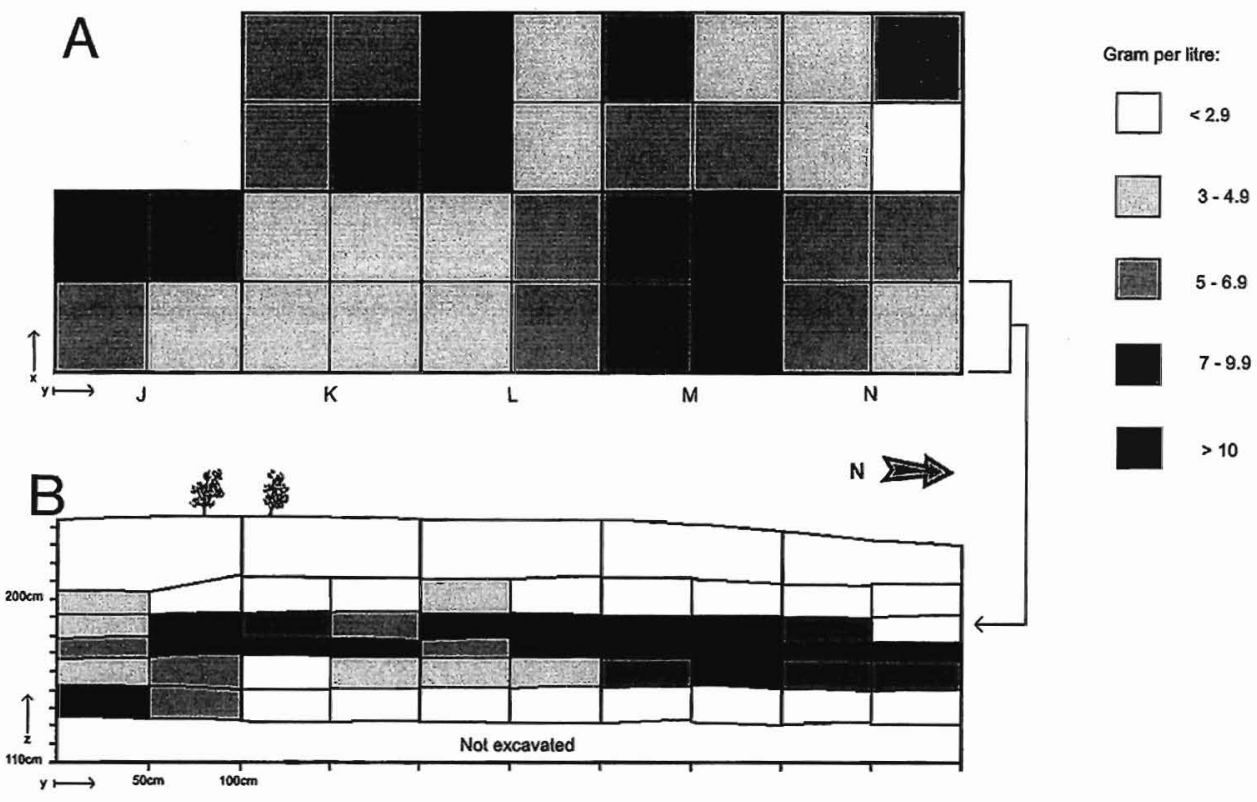

Fig. 4. Density of potsherds in Krek 52/62, Unit II, 1998. A: horizontal distribution, all levels. B: north-south profile.

Table I. Fragments of Glass Bangles from Krek 52/62, Unit II

\begin{tabular}{lccccll}
\hline SQUARE \# & $\begin{array}{c}\text { WIDTH } \\
(\mathrm{mm})\end{array}$ & $\begin{array}{c}\text { HEIGHT } \\
(\mathrm{mm})\end{array}$ & $\begin{array}{c}\text { WIDTH/ } \\
\text { HEIGHT } \\
\text { RATIO }\end{array}$ & $\begin{array}{c}\text { FACETTE } \\
(\mathrm{mm})\end{array}$ & \multicolumn{1}{c}{ COLOR } & $\begin{array}{c}\text { FLAW } \\
\text { FREQUENCY }\end{array}$ \\
\hline M9/13 & 13.0 & 6.5 & 2.0 & 1.0 & Dark green & Few \\
L8/12 & 13.5 & 6.8 & 1.99 & 1.3 & Light green & Numerous \\
K13/1 & 12.6 & 6.4 & 1.97 & $1.0-1.4$ & Light green & Few \\
J11/5 & 11.7 & 6.0 & 1.95 & 1.0 & Light green & Few \\
M12/3 & 11.3 & 5.0 & 2.26 & - & Light blue-green & Few \\
\hline
\end{tabular}
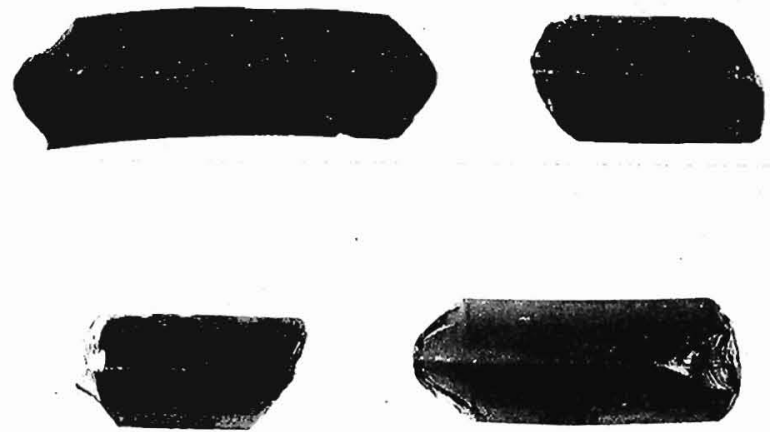

Fig. 5. The fragments of glass bracelets uncovered in Krek 52/62, Unit II, squares M9, L8, J11, K13. The bangles were made from translucent light green to dark green glass. (Photo by Hilde Jensen) 


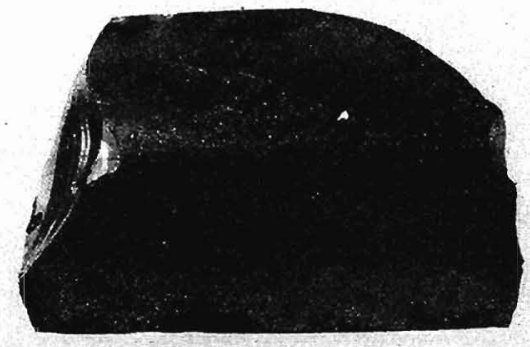

Fig. 6. The fragment of a glass bangle uncovered in Krek 52/62, Unit II, square M12. The bracelet was made from translucent light blue-green glass. (Photo by Hilde Jensen)

tion of potash. The $\mathrm{K}_{2} \mathrm{O}: \mathrm{Na}_{2} \mathrm{O}$ ratios range from 0.18 to 0.27 and are very low for mixed-alkali glasses. The light blue-green glass of M12/3 lacks nearly any flux, which might be due to leaching processes. All of the glass shows a low content of lime ( $\mathrm{CaO} 1.65-3.06$ percent), only traces of barium are documented $(\mathrm{BaO}$ 0.01-0.06 percent). Characteristic for the glass from Krek is the very high value of alumina $\left(\mathrm{Al}_{2} \mathrm{O}_{3} 6.78-7.75\right.$ percent). Due to the chemical composition of the bangles, there are no signs of weathering (at least superficially), despite the acidic soil conditions at Krek: "The high alumina contents greatly improve the chemical durability and, hence, those ... glasses rarely show any signs of weathering" (Brill 1987 :5). Brill based his statement on examinations of glass with an alumina content of about 5 percent; the Krek bangles show significantly higher values.

The chemical composition analyses of the glass give no hint where the ornaments were produced, but they may trace the provenience of the raw materials or

Table 2. Chemical Analysis of the Glass Fragments from Krek 52/62, Unit II

\begin{tabular}{lccccc}
\hline & $\mathrm{M} 9 / 13$ & $\mathrm{~L} 8 / 12$ & $\mathrm{~K} 13 / 1$ & $\mathrm{~J} 11 / 5$ & $\mathrm{M} 12 / 3$ \\
\hline $\mathrm{SiO}_{2}$ & $66.28 \%$ & $72.86 \%$ & $70.17 \%$ & $71.98 \%$ & $74.20 \%$ \\
$\mathrm{Na}_{2} \mathrm{O}$ & $15.82 \%$ & $5.76 \%$ & $9.78 \%$ & $7.38 \%$ & $0.17 \%$ \\
$\mathrm{~K}_{2} \mathrm{O}$ & $2.88 \%$ & $1.53 \%$ & $2.06 \%$ & $1.87 \%$ & $0.53 \%$ \\
$\mathrm{~K}_{2} \mathrm{O}: \mathrm{Na}_{2} \mathrm{O}$ & 0.18 & 0.27 & 0.21 & 0.25 & $(3.12)$ \\
$\mathrm{Al}_{2} \mathrm{O}$ & $7.75 \%$ & $3.06 \%$ & $6.78 \%$ & $7.43 \%$ & $6.82 \%$ \\
$\mathrm{CaO}$ & $2.11 \%$ & $2.53 \%$ & $2.74 \%$ & $1.65 \%$ \\
$\mathrm{FeO}$ & $1.86 \%$ & $1.53 \%$ & $2.01 \%$ & $2.11 \%$ & $2.12 \%$ \\
$\mathrm{MgO}$ & $1.14 \%$ & $0.23 \%$ & $0.35 \%$ & $1.24 \%$ & $0.72 \%$ \\
$\mathrm{TiO}$ & $0.42 \%$ & $0.08 \%$ & $0.11 \%$ & $0.39 \%$ & $0.38 \%$ \\
$\mathrm{MnO}$ & $0.08 \%$ & $0.40 \%$ & $0.40 \%$ & $0.37 \%$ & $0.09 \%$ \\
$\mathrm{P}_{2} \mathrm{O}$ & $0.49 \%$ & $0.03 \%$ & $0.04 \%$ & $0.02 \%$ & $0.37 \%$ \\
$\mathrm{BaO}$ & $0.06 \%$ & $0.24 \%$ & $0.08 \%$ & $0.10 \%$ & $0.01 \%$ \\
$\mathrm{Cl}$ & $0.28 \%$ & & $0.21 \%$ & $0.21 \%$ \\
\hline
\end{tabular}

Note: M9/13: mean of 14 measurements (standardized to 100\%) on different parts of the fragment with a microprobe (Geochemical Institute of the University of Göttingen, Germany, Hans Wedepohl). L8/12, K13/1, J11/5, M12/3: mean of five (M12/3: six) measurements on different parts of the fragments with a microprobe (Geochemical Institute of the University of Tübingen, Udo Neumann). 

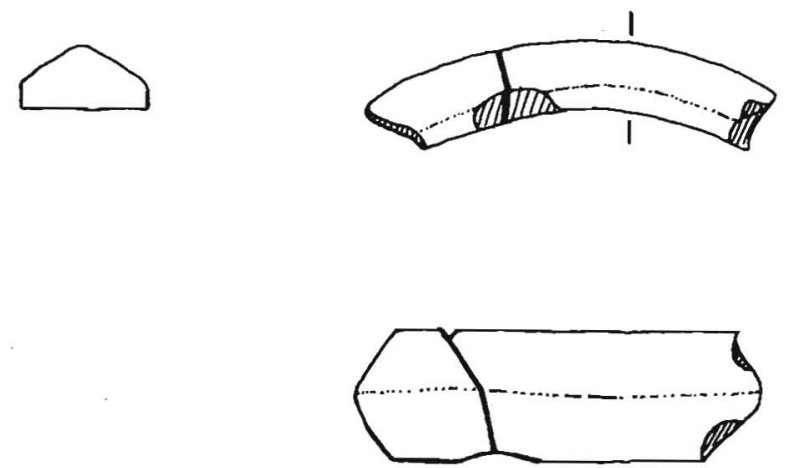

Fig. 7. The fragment of a glass bracelet uncovered in Krek $52 / 62$, Unit II, square M9. The inner diameter of the bangle can be reconstructed to $58 \mathrm{~mm}$.

the areas of production of glass cullets. According to Glover and Henderson (1995), three regions have to be considered as early production centers for Southeast Asian glass: (a) India, (b) China, and (c) the Mediterranean. For the Indian glass, soda was used as the main alkali (14-17 percent), the values of potash are low (0.5-3 percent) (Brill 1987:17-18). Typically the levels of alumina are high $\left(\mathrm{Al}_{2} \mathrm{O}_{3}>3.5-4\right.$ percent $)$ and the value for lime lies below 4.5-5 percent (Brill 1987:4). Glover and Henderson (1995:153-154) state that most of the glass from Arikamedu contain even more aluminum and less calcium than Brill's typical Indian glass.

In comparison, Roman glass shows lower alumina content $\left(\mathrm{Al}_{2} \mathrm{O}_{3}<3.5-4\right.$ percent), higher values of lime ( $\mathrm{CaO}>4.5-5$ percent) (Brill 1987:145) and less titanium oxide than Indian glass (Brill 1987:153). Mixed-alkali glass is rare, sodalime glass is predominant (Brill 1987: 141, 153).

Typically, early Chinese glass is rich in barium and lead, although in southern China some potassium glasses are also found that may have been produced locally (Brill 1987 : 159). Analyses from Vietnamese Iron Age glass (Nguyen Truong Ki 1983, cited in Glover and Henderson $1995: 153$ ) showed two different groups of glass masses: probably locally produced potassium glasses with low $\mathrm{Na}, \mathrm{Pb}$, and $\mathrm{Al}$ values from the Dong Son context and soda-lime glass with very high alumina values ( $>5$ percent) from the Sa Huynh context. At the Sa Huynh site of Giong Ca Vo, Can Gio district, near Ho Chi Minh City (Francis 1995:5-6; Nguyen Kim Dung 1995), evidence was found for local glass production: beside glass ornaments and fritty waste glass, three pits were discovered containing white sand, which is interpreted as raw material for the glass mass.

The results of recent Vietnamese research allow the postulation of at least four early production centers of glass mass used in Southeast Asia in the last centuries B.C. and shortly after: (a) India with mixed-alkali glass, low lime, and high alumina contents, (b) China with barium-lead glass, (c) the Mediterranean with mainly soda-lime glass with high values of lime and a smaller amount of alumina, and (d) South China and North Viet Nam with potassium glass showing only small values of $\mathrm{Na}, \mathrm{Pb}$, and $\mathrm{Al}$. It is probable that South Viet $\mathrm{Nam}$ can be named as a fifth center for soda-lime glass with very high alumina content and Giong $\mathrm{Ca}$ 
Vo as one of the glass production sites. The existence of further glass production centers, e.g., in south Thailand as proposed by Bennett Bronson (1990:226), have not been proved yet (Glover and Henderson $1995: 149$ ).

The chemical composition of the glass bangles from Krek 52/62 are most similar to the values of the Indian mixed-alkali glass or the South Vietnamese sodalime glass with very high amounts of alumina. They show no similarities to the known Mediterranean soda-lime, Chinese lead-barium, or South Chinese-North Vietnamese potassium glasses.

\section{COMPARATIVE GLASS SPECIMENS}

Glass bangles comparable to those from Krek have been found in Viet Nam, Thailand, and the Philippines. An almost twin piece is exhibited at the Museum of Vietnamese History in Ho Chi Minh City. The exhibition label yielded information about Do Trang Suc Bang Tiec, a personal ornament made of tin, and so it is likely to have been mixed up. I had no opportunity to get evidence regarding the provenience of the glass bangle or its dating. Like the one from Krek, this bracelet is made from translucent dark green glass and shows a similar houseshaped cross section. The dimensions seem to be similar to the Cambodian piece.

Several glass bangles with triangular cross sections in dark green, black, and violet are reported from the glass production and jar burial site of Giong $\mathrm{Ca}$ Vo near Ho Chi Minh City. Fritty waste glass in dark green and black point to a local production of the ornaments (Francis 1995:5), which were likely "made by expanding beads into rings working at a furnace" (Francis 1995:6). Additionally, glass bracelets with different cross sections were found at the site (Andreas Reinecke pers. comm.).

From Go Ma Voi, a Sa Huynh jar burial site in Quang Nam Province, at least one fragment of a bangle with a triangular cross section is known (Reinecke et al. 2002). Around two dozen metal age sites of the second half of the first millennium B.C. revealed glass bangles with triangular and semicircular cross sections. The majority of the bracelets, mainly made from green, blue-green to blue translucent glass, originates from graves of Dong Son context (e.g., Xuan Lap, Lang Vac, Dong Mom) or jar burials of Sa Huynh context (e.g., Giong Phet, Ban Tram, Suoi Chon, Phu Hoa, Dan Giay, Tam My) (Fontaine 1972:437-438; Andreas Reinecke pers. comm.).

Another parallel is reported from Ban Don Ta Phet, an early Iron Age burial ground in Kanchanaburi Province, west Thailand, which also yielded several other glass bangles. The translucent pale green glass bangle (sf. No. 6084, context 325) was discovered in the 1984-85 field campaign (Glover 1990:170) and is dated to the first half of the fourth century B.C. (Glover 1990:155). Remarkable is the cross section, which again resembles a flattened house shape. The inner diameter of this bracelet measures between 54 and $63 \mathrm{~mm}$. Height $(32.6 \mathrm{~mm})$ and width $(15.2 \mathrm{~mm})$ are markedly larger than the corresponding values from the Krek fragment, but the height-width ratio of the Ban Don Ta Phet bracelet (2.14) lies well within the range of the Cambodian pieces (1.95-2.26). Unfortunately the chemical analyses of the bangle from Ban Don Ta Phet did not yield reliable results because the find was too decayed (Glover 1990:170).

In Area $\mathrm{C}$ of Manunggul Cave, one of the Tabon sites on Palawan, Philippines, three bangles with triangular cross sections made from clear green glass 
were discovered in Sa Huynh-related contexts in jar burials (Fox 1970:118). Another jar burial site on the Philippines, Makabog on Masbate Island, yielded fragments of glass bangles dating to the Iron Age (Henson 1992 : 213).

Some sites in India also report bangles with triangular cross sections. A green one "with a row of yellow studs round the outer edge" originates from Atranjikhera IV and is dated between 600 and 50 B.C. A light brown one was found at Hastinapur II, which dates to $1100-800$ B.C. (Lal 1987:44).

According to Glover and Henderson (1995) the production of true glass (not faience) started in India between 1000 and 800 B.C. In Southeast Asia, glass is only found in contexts dated younger than 500 B.C. The trade of glass items or perhaps glass cullet, which may be locally reworked, seems to accompany the first use of iron (Glover and Henderson 1995:148-149). The earliest finds of glass in Southeast Asia are reported from Thailand (e.g., Ban Don Ta Phet) and from the Sa Huynh culture of central and southern Viet Nam in beads as well as bangles. Most of the finds of glass bangles with triangular cross sections were made in Viet Nam in the Iron Age contexts of Dong Son and especially the Sa Huynh culture. Some sites with this type of glass ornament outside of Viet Nam, such as Ban Don Ta Phet in Thailand or Manunggul Chamber B/Tabon Caves, Philippines, also show a strong relationship to the Sa Huynh context. The association with doubleheaded animal pendants and other ornaments made from stone or glass characteristic for Sa Huynh is documented from both sites (Fox 1970; Glover 1990:166; Reinecke 1994). The small fragments of green glass bracelets with triangular to house-shaped cross sections from Krek 52/62 can therefore imply a not yet clearly defined connection between the Mimotien complex and Iron Age Sa Huynh.

\section{IMPLICATION OF GLASS FINDS FOR DATING THE 'MIMOTIEN COMPLEX'}

Up to now the Mimotien material culture is rather coarsely studied, only a few circular earthworks have been partly excavated (Albrecht et al. 2001; Dega et al. 2000). Groslier $(1966 a, 1966 b)$ spoke of 14 cultural layers that he claimed to have discovered at one of the earthwork sites. Heang (1999) and Thuy (1999), however, recovered only one occupational layer when they dug a test pit at Groslier's site in 1998. Additionally, photographs in the report of Groslier to the EFEO in 1962 point to artificially made archaeological horizons in regular steps rather than to original cultural layers. The recently excavated Mimotien samples from Krek 52/62 (Heng and Mao 1999; Heng and Som 1999), Phoum Beng (Chhor et al. 1999), Phoum Kampoan, and the Groslier site (Heang 1999; Thuy 1999) are homogeneous in their range of pottery and stone artifacts. Some variations in pottery decoration style between the different sites are regarded as local variants rather than indicative of chronological difference. Within each of the sites only one occupational layer could be observed, which seem to be quite homogeneous. Detailed future investigations will show if there are slight changes through time or not.

The time range of the Mimotien cultural complex as well as of the occupational phases of each of the circular earthworks is not clearly understood. Only recently Michael Dega et al. (2000) presented five radiocarbon dates based on the organic temper of the pottery from four earthworks. The dates range from $2290-$ 2030 B.C. (95.4 percent) from the deepest part of the occupational layer at Trameng earthwork near Memot to 400-350 B.C. (44.0 percent) or 320-200 B.C. 
(51.4 percent), respectively, from the top of the occupational layer at Chi Peang earthwork near Krek. The dates, however, have to be viewed with caution. The use of organic temper as the basis for radiocarbon dates is problematic due to technical difficulties in sample processing (Georges Bonani, pers. comm.). First attempts to obtain direct accelerator dates from the organic tempered pottery from Krek 52/62 did not yield reliable results: they seem to be too old (Albrecht et al. 2001). Whether the single earthworks were settled for several hundred years or less than 50 years remains an open question, as well as the total time span of the Mimotien complex.

Thus far, the glass bangle fragments from Krek 52/62 give the clearest dating evidence of the earthen structures. They were found in the uppermost part but well within the occupational layer of the earthwork. There is no evidence that these ornaments are intrusive or that any other artifacts of this stratigraphic zone stand out from the sample from underlying zones. Nothing points to a second short-term settlement apart from the Mimotien remains.

Looking at other finds of early glass from Southeast Asia, there is no argument for dating the glass bracelets earlier than 500 B.C. except that they may be the first that have been discovered that are older. Supposing the fragments really belong to the singular homogeneous occupational layer of Krek 52/62 (Sok and Vin 1999), which is part of the same cultural complex as the other circular earthworks, it can be assumed that at least the terminal phase of the Mimotien complex was contemporaneous to Iron Age Ban Don Ta Phet and Sa-Huynh or even younger. Therefore, a date to the second half of the first millennium B.C. is most probable.

\section{EVIDENCE FROM OTHER MIMOTIEN ARTIFACTS}

Pottery and polished stone artifacts from the Mimotien circular earthworks lack detailed comparative examination and are not chronologically significant thus far. Several spindle whorls found at Krek $52 / 62$ point to a date in the first millennium B.C. (Albrecht et al. 2001). The other ornaments in Mimotien contexts beside the glass bangles consist of heavy stone bracelets with triangular cross sections (Groslier site: Thuy 1999), very fine stone bracelets with rectangular cross sections (Groslier site: Thuy 1999; Krek 52/62: Heng and Mao 1999; Albrecht et al. 2001), and a garnet bead from Krek 52/62 (Albrecht et al. 2001). Other than the biconical drilling, the nearly triangular natural form of the precious stone was not fashioned. The chronological evidence for these ornaments is weak.

The lack of metal artifacts and molds, which previously led to the dating of the Mimotien culture to the Neolithic period, is also not very indicative. Bennett Bronson (1992:104) assumes a profusion of mining and ore processing centers on regional levels in Southeast Asia during the late prehistoric times, mining poorer quality ores. He questions, however, the supposition that every village had its own metal production specialist and points to the easy tradability of metal and metal artifacts.

The absence of molds in Mimotien context can reflect two different things: (a) there are no molds at the sites, or (b) the casts have not been found yet. If there were no molds at the sites this would only prove that they were not used, stored, or discarded within the circular structures. Whether casts were not used at all or the Mimotien metal processing was located somewhere outside the earthworks cannot be stated. If metal was present or even common at these Mimotien sites, it 
would be very likely that it vanished due to the acidity of the soil. The red tropical soil, which characterizes the region the circular earthworks are limited to, shows a $\mathrm{pH}$ value $<4$ (Albrecht et al. 2001). In conclusion, our actual knowledge is too fragmentary to decide from the absence of molds and metal artifacts whether the Mimotien was true Neolithic, chronologically Iron Age without its own metallurgy, or true Iron Age with independent metal processing.

Furthermore, in Unit II in Krek 52/62 two artifact concentrations with several complete large and small vessels, including a footed bowl and other accompanying outstanding artifacts, have been documented. Due to the acidic soil, no organic remains could be traced. However, the circumstances argue for the interpretation of several well-preserved and clearly deposited vessels as jar burials (Albrecht et al. 2001). Jar burials are not very common in the prehistory of mainland Southeast Asia but these are well known from the regionally neighboring Sa Huynh culture (Reinecke 1994, 1996).

Even if the other finds from the circular earthworks in eastern Cambodia and southern Viet Nam do not yield support for an Iron Age date of at least the terminal phase of the Mimotien complex, they do not challenge this interpretation.

\section{CONCLUSIONS}

The fragments of five glass bangles from Krek 52/62 are singular finds in Mimotien assemblages. There is no evidence that these were intrusive artifacts and the good preservation of the fragments is due to their chemical composition. The chemical analyses of the bangles point to an origin of the glass in India or South Viet Nam. Parallel finds of translucent dark green, pale green, black, and violet glass bracelets with triangular to house-shaped cross sections are known from Viet Nam, Thailand, and the Philippines. Thus far, early glass in Southeast Asia is only documented in contexts younger than 500 B.C. and seems to accompany the first use of iron. Bangles similar to the Krek specimens are predominantly found in Iron Age Sa Huynh or Sa Huynh-related contexts dated to the second half of the first millennium B.C.

These assumptions can lead to three different possibilities of interpretation:

1. The fragments are contemporaneous with their parallel finds, but not with the occupational layer at Krek 52/62. They are intrusive. In this scenario the glass bracelets from Krek give no hint for the dating of the Mimotien sites.

2. The fragments are not intrusive. They are contemporaneous with the earthwork structures and the upper part of the occupational layers at Krek. However, they are not contemporaneous with the parallel finds. As a consequence, the glass bracelets from Krek could be the first proof of glass in Southeast Asia dating earlier than 500 B.C.

3. The fragments are not intrusive. They are contemporaneous with the earthwork structures and the upper part of the occupational layers at Krek. And they are contemporaneous with the parallel finds. Following this line of argument, the Mimotien has to be redated: at least its terminal phase reached to the second half of the first millennium B.C.

The third interpretation is based on the strongest indications. I prefer this interpretation until new finds, comparative pottery analyses, or more reliable absolute dating provide better evidence. 


\section{ACKNOWLEDGMENTS}

I am deeply grateful to my colleagues Heng Sophady, Sirik Kada, Thuy Chanthourn, Vin Laychour, Gerd and Barbara Albrecht, Andreas Reinecke, Michael Dega, Nguyen Trung Do, Ian Glover, and Peter Francis for the many fruitful discussions and all the information they shared with me. Furthermore, I want to thank the Department of Archaeology of the Royal University of Fine Arts, Phnom Penh, and its Dean Hor Lat as well as H. E. Chuch Phoeurn, Ministry of Culture and Fine Arts, Cambodia, for their organizational support. This study would not have been possible without the financial support of the German Academic Exchange Service (DAAD) and the Ministry of Science, Research and Art of Baden-Württemberg, Germany.

\section{REFERENCES CITED}

Albrecht, G., and M. N. Haidle

1999 Im Schatten von Angkor Vat? Archäologie in Deutschland 3/99:14-19.

Albrecht, G., M. N. Haidle, Sivleng Chhor, leang Hong Heang, Sophady Heng, Someaphyvath Mao, Kada Sirik, Sophal Som, Chanthourn Thuy, and Laychour Vin

2001 Circular earthwork Krek 52/62: Recent research on the prehistory of Cambodia. Asian Perspectives 39(1-2): 20-46.

BelliwoOd, P.

1978 Man's Conquest of the Pacific. The Prehistory of Southeast Asia and Oceania. Auckland, Sydney, and London: Collins.

BRILL, R. H.

1987 Chemical analyses of some early Indian glasses, in Archaeometry of Glass: 1-25, ed. H. C. Bhardwaj. XIV International Congress on Glass, 1986, New Delhi, India. Calcutta: Indian Ceramic Society, Central Glass and Ceramic Research Institute.

BRONSON, B.

1990 Glass and beads at Khuan Lukpad, Southern Thailand, in Southeast Asian Archaeology 1986, Proceedings of the First Conference of the Association of Southeast Asian Archaeologists in Western Europe: 213-229, ed. I. Glover and E. Glover. Oxford: BAR International Series 561.

1992 Patterns in the early Southeast Asian metal trade, in Early Metallurgy, Trade and Urban Centres in Thailand and Southeast Asia: 63-114, ed. I. Glover, P. Suchitta, and J. Villiers. Bangkok: White Lotus.

Carbonnel, J.-P.

1979 Recent data on the Cambodian Neolithic: The problem of cultural continuity in southern Indochina, in Early South East Asia: 223-226, ed. R. B. Smith and W. Watson. Oxford: Oxford University Press.

Chror, Sivleng, Kada Sirik, AND Thol Un

1999 Beng circular earthworks. Unpubl. final thesis, Faculty of Archaeology, Royal University of Fine Arts, Phnom Penh.

DEGA, M. F.

1999 Circular settlements within eastern Cambodia. Bulletin of the Indo-Pacific Prehistory Association 18: 181-190.

Dega, M. F., L. Poch, U. Moninitha, and C. Samouen

2000 The timing of Cambodian earthworks. Paper presented in the symposium 'Recent Advances in Southeast Asian Archaeology' at the $65^{\text {th }}$ meeting of the Society for American Archaeology, Philadelphia, Pennsylvania.

FontAINE, H.

1972 Nouveau champs de jarres dans la province de Long-Khanh. Bulletin de la Société des Etudes Indochinoises 47:397-486.

Fox, R. B.

1970 The Tabon Caves: Archaeological Explorations and Excavations on Palawan Island, Philippines. Manila: National Museum of Manila, Monograph no. 1. 
Francis, P. JR.

1995 Beads in Vietnam: An initial report. The Margaretologist 8(2):3-9.

Glover, I. C.

1990 Ban Don Ta Phet: The 1984-85 excavation, in Southeast Asian Archaeology 1986, Proceedings of the First Conference of the Association of Southeast Asian Archaeologists in Western Europe: 139-183, ed. I. Glover and E. Glover. Oxford: BAR International Series 561.

Glover, I., AND J. Henderson

1995 Early glass in South East Asia and China, in South East Asia and China: Art, Interaction and Commerce: 141-170, ed. R. Scott and J. Guy. Colloquies on Art and Archaeology in Asia No. 17, Percival David Foundation of Chinese Art, University of London, London.

Groslier, B. P.

1962 Programme de recherches urgentes à Angkor. Rapport Interimaire de Janvier 1962. Unpubl. report to the École Française d'Extrême Orient at Siem Reap, Cambodia.

1966a Archaeologia Mundi: Indochina. Geneva: Nagel.

1966 bécouvertes archéologiques récentes au Cambodge. Kambuja 2(16): 76-81. Phnom Penh.

Heang, Leang Hong

1999 The pottery from Groslier circular earthworks site, stored in the National Museum Phnom Penh. Unpubl. final thesis, Faculty of Archaeology, Royal University of Fine Arts, Phnom Penh.

Heng, Sophady, and Sophal Som

1999 Analysis of pottery from circular earthworks Krek 52/62. Unpublished final thesis, Faculty of Archaeology, Royal University of Fine Arts, Phnom Penh.

Heng, Than, and Someaphyvath MaO

1999 Study of stone tools from circular earthworks Krek 52/62. Unpublished final thesis, Faculty of Archaeology, Royal University of Fine Arts, Phnom Penh.

Henson, F. G.

1993 Jar burial excavations in the Philippines, in Early Metallurgy, Trade and Urban Centres in Thailand and Southeast Asia: 213-225, ed. I. Glover, P. Suchitta, and J. Villiers. Bangkok: White Lotus.

Нigham, C.

1996 The Bronze Age of Southeast Asia. Cambridge: Cambridge University Press.

Kojo, Yasushi, and Syrha Pheng

1997 A newly discovered earthwork in southeastern Cambodia. Anthropological Science $105(3): 181-187$.

LAL, B. B.

1987 Glass technology in early India, in Archaeometry of Glass: 44-56, ed. H. C. Bhardwaj. XIV International Congress on glass 1986, New Delhi, India. Calcutta: Indian Ceramic Society, Central Glass and Ceramic Research Institute.

LUONG NinH

1985 Circular earthworks. Khao Co Hoc 1985/3. (In Vietnamese.)

MAlleRet, L.

1959 Ouvrages circulaires en terre dans l'Indochine Méridionale. Bulletin de l'École Française de l'Extrême Orient 49:409-434.

MOURER, R.

1977 Laang Spean and the prehistory of Cambodia. Modern Quaternary Research in Southeast Asia 3:29-56. Rotterdam.

1994 Contribution a l'étude de la préhistoire du Cambodge, in Recherches Nouvelles sur le Cambodge: 143-195, ed. F. Bizot. Paris: École Française d'Extrême-Orient.

NGUYen Kim DUNG

1995 Ornaments from jar burial sites in Can Dio district, Ho Chi Minh City. Khao Co Hoc 1995/2:27-46. (In Vietnamese).

NGUYen TRUNG Do

1984 Loc Ninh circular earthwork, in Oc-eo Culture and Ancient Culture in the Mekong Delta. Long Xuyen Publishing House. (In Vietnamese.)

1997 Problems of research on Bhin Phuoc circular earthworks, in Archaeological Problems in the South of Vietnam. Social Sciences Publishing House. (In Vietnamese.) 
1999 Circular earthworks in Binphuoc province. Paper presented at the conference on Circular earthworks in Cambodia, 14-19 September 1999, Phnom Penh.

Nguyen Truong Kr

1983 Initial research on glass making in Vietnam. Khao Co Hoc 1983/1:47-54. (In Vietnamese.)

NGUYen VAN Long

1986 Circular earthworks in Song Be province. Khao Co Hoc 1986. (In Vietnamese.)

Pham Duc Manh

1996 Proto-history and pre-history of the eastern part of Nam Bo-past and modern perceptions. Vietnamese Studies 1996/2, special: archaeological data II, new series 50(120):63119.

REINECKE, A.

1994 Die metallzeitliche Sa-Huynh-Kultur in Vietnam und ihre Gefäßgräber. Beiträge zur Allgemeinen und Vergleichenden Archäologie 14:95-125.

1996 Ohrringe mit Tierkopfenden in Südostasien. Beiträge zur Allgemeinen und Vergleichenden Archäologie 16:5-51.

Reinecke, A., ANd Le Duy Son

2000 Ein neu entdecktes Gräberfeld der Sa Huynh-Kultur von Gò Mùn in Mittelvietnam. Beiträge zur Allgemeinen und Vergleichenden Archäologie 20:5-44.

Reinecke, A., Nguyen Chieu, and Lam My Dung

2002 Neue Entdeckungen zur Sa-Huynh-Kultur: Das Gräberfeld Go Ma Voi in der Provinz Quang Nam und das kulturella Umfeld in Mittelvietnam. Köln: Lindensoft.

SAURIN, E.

1969 Les recherches préhistoriques au Cambodge, Laos et Vietnam (1877-1966). Asian Perspectives $12: 27-40$.

1971 Nouvelles observations préhistoriques à l'est de Saigon. Bulletin de la Société des Études Indochinoises 43.

SOK, KimSAN, AND LAYCHOUR VIN

1999 Stratigraphy and settlement pattern of circular earthworks Krek 52/62. Unpubl. final thesis, Faculty of Archaeology, Royal University of Fine Arts, Phnom Penh.

Thux, Chanthourn

1999 Groslier circular earthworks site in Memot District. The stone tools in the National Museum Phnom Penh. Unpubl. final thesis, Faculty of Archaeology, Royal University of Fine Arts, Phnom Penh.

WALES, H.G.Q

1957 Pre-History and Religion in Southeast Asia. London.

\section{ABSTRACT}

Until recently the Mimotien complex of southeast Cambodia and adjacent Viet Nam was dated to the Neolithic. The artifact assemblages of circular earthworks with outer walls and inner ditches consisted only of ceramic and stone artifacts: absolute dating of the organic temper of the pottery did not yield reliable results. Other organic material and metal artifacts have not been preserved due to the acidity of the red tropical soil with a pH value of less than 4. In 1998 and 2000, fragments of five glass bangles were discovered in the upper part of the excavation but well within the occupational layer of the earthwork Krek 52/62. The chemical composition of the translucent green bracelets (with triangular to house-shaped cross sections) points to an origin of the glass in India or South Viet Nam, respectively. High alumina content prevented intensive weathering. Glass is introduced in Southeast Asia in the second half of the first millennium B.C. Parallel finds of green to blue translucent glass bracelets with triangular to house-shaped cross sections from Viet Nam, Thailand, and the Philippines date to the second half of the first millennium B.C. The glass bangles from Krek 52/62 indicate a date of at least the terminal phase of the Mimotien complex to 500 B.C. or even younger. KEYwords: Cambodia, circular earthworks, Mimotien, early glass, Neolithic, Iron Age. 